\title{
Medios, e-medios y remedios
}

institucionales.us.es/ambitos/

\section{Jorge Abelardo Cortés Montalvo}

Universidad Autónoma de Chihuahua (México)

jcortes@uach.mx

English Version: Media, e-media and remedies

El autor reflexiona y argumenta con datos la correlación entre los contenidos que se proyectan a los públicos, las nuevas herramientas digitales que se utilizan para esa transmisión y lo que se deriva de todo ello: la necesidad ineludible de preparar a los receptores desde sus inicios educativos para afrontar este desafío macro-mensajístico, lo cual quiere decir alfabetización mediática por medio de la educomunicación como disciplina indispensable para que la mente crítica del futuro ciudadano

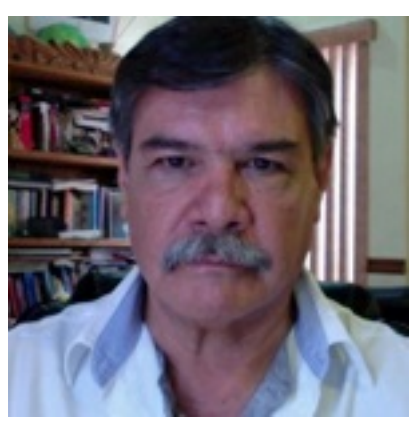
vaya formándose con vistas a un fortalecimiento de la democracia. El ciudadano con formación en la recepción de mensajes comunicacionales es capaz de distinguir entre contenidos importantes y rigurosos y espectáculos más o menos anodinos.

En el convulsionado mundo de la era digital, tres aspectos adquieren notoriedad como motivo de preocupación en torno a la participación de la comunicación en la relación política, tecnológica y social. El primero se relaciona con los contenidos, que en el terreno político continúa siendo premisa noticiosa aquello que se acerque al desastre o en extremo opuesto, al espectáculo. El segundo tiene que ver con la deriva de los medios tradicionales o convencionales hacia formatos y modalidades donde las tecnologías digitales van ganando terreno y en el tercero la reflexión conduce al territorio de la educación mediática.

Palabras clave: mensajes, mente crítica, educomunicación.

Abstract: The author reflects and argues with data the correlation between the contents that are projected to the public, the new digital tools that are used for that transmission and what is derived from all this: the unavoidable need to prepare the receivers from their educational beginnings to face this macro-messaging challenge, which means, media literacy through education, as an indispensable discipline for the critical mind of the future, citizen to be formed with a view to strengthening democracy. The citizen with training in the reception of communication messages is able to distinguish between important and more rigorous content and smaller and blander.

In the convulsive world of the digital age, three aspects acquire notoriety as a reason for concern regarding the participation of communication in the political, technological and social relationship. The first is related to the content, which in the political field continues being a news premise that approaches disaster or at the opposite extreme, the spectacle. 
The second is about the derivation of traditional or conventional media towards formats and ways of life where digital technologies are gaining ground and in the third, reflection leads to the territory of medical education.

Keywords: messages, critical mind, educommunication.

\section{MEDIOS: tendencias del contenido de la comunicación política.}

Los medios y gobiernos, en cualquier democracia que se precie, tradicionalmente marchan de la mano, unos y otros pulsan, ejercen y miden su poder. Se dice con frecuencia que los gobiernos manipulan a la población a través de los medios, pero también se dice que los medios son el contrapeso del poder gubernamental, en no pocas ocasiones han cumplido la ingente labor de "destapa cloacas". La verdad es que hay muchas sutilezas en la relación medios, gobierno y ciudadanía informada.

En un contexto global, es necesario echar mano de un formato actualizado para considerar la comunicación, dejando atrás el viejo e inoperante esquema lineal de emisor-códigomensaje-canal-receptor. Se abre un espectro multidimensional que toma en cuenta no solo la generación y flujo de códigos lingüísticos encapsulados en mensajes, sino también el dominio de competencias digitales, de la capacidad de las audiencias en la selección, recuperación, análisis y generación de información, su colocación en una diversidad de medios interactivos, sobre todo a través de muy variados dispositivos y aplicaciones electrónicos, y muy importante, una dimensión o ámbito ético emocional, o como apuntan Gabelas, Marta y Hergueta (2013), de tipo relacional, que empata con la generación de mensajes propios del sujeto de la comunicación, y su colocación en diferentes circuitos tales como blogs y redes sociales.

Este aspecto, el factor emocional, que desde tiempo atrás ha sido explotado por la publicidad, moviendo la fibra sensible o sensiblera, con fines comerciales, es ahora utilizado por medios y gobiernos, en un sentido que mueve a las audiencias en un continuo que va desde la inquietud hasta la angustia y que mantiene a la ciudadanía al filo de la incertidumbre, tratando, con cierto oportunismo, de sacar ventaja política de ello. Es una referencia, en efecto, a las estrategias de control, a través del miedo, que diversos grupos de poder despliegan sobre la población.

No es un secreto que las características de lo noticioso, en la relación que se establece entre audiencias y medios, han sabido ser aprovechadas con fines de disuasión. Ejemplo elocuente es la relevancia que la dieta noticiosa, teñida de rojo por lo regular y bajo la premisa de que "nada puede estar tan mal, tan mal, que no pueda estar peor", manda un mensaje de la esfera en el poder o bien de la oposición, a la ciudadanía, del tipo,... "ya lo ven, sin nosotros podría ser peor", y pocas veces la cobertura mediática se orienta en el sentido de deslindar y asumir o señalar con claridad la responsabilidad en las situaciones críticas.

Los objetos de temor son múltiples, desde los desastres naturales tales como los terremotos, huracanes o inundaciones, hasta el peligro que representan entidades inespecíficas, como los terroristas, las mafias del narcotráfico o los populistas. 
Esta situación se aprecia de manera más marcada en países que enfrentan una suerte de ingobernabilidad, resultado de estructuras legales y judiciales débiles y un sistema de permanencia en el poder de una élite política sustentada en la administración de la pobreza, como México.

Es cierto que vivimos tiempos violentos; De acuerdo con cifras emitidas por la organización "Gun Violence Archive", durante el año 2017 se registraron en los Estados Unidos de Norteamérica, país que suele ser un referente global, 61.460 incidentes relacionados con armas de fuego. Como consecuencia de tales agresiones, 15.597 personas perdieron la vida, mientras que 31.179 resultaron con lesiones.

En México, según reporte del Sistema Nacional de Seguridad Pública, durante 2017 se registraron 129.422 delitos del fuero común, de los cuales se cuentan en el país 46.750 homicidios, tres veces más que en los Estados Unidos, 1.390 secuestros y 5.786 extorsiones (SNSP, 2017).

La información vertida por los medios, analizada en profundidad, difícilmente nos provee de elementos para saber a ciencia cierta quien o quienes son responsables de esta situación o cómo y por qué se ha permitido esta involución social. Antes bien, estos vectores informativos son utilizados para mantener una "sicosis de la inseguridad", una especie de terrorismo mediático, que hace víctimas incluso a los periodistas. La Unesco tiene registrados y documentados más de 70 homicidios de periodistas en México en los últimos 10 años, más o menos uno cada dos meses en promedio, tan solo en el 2017, 12 periodistas fueron asesinados por razones relacionadas con el ejercicio de su profesión y persiste, hasta la fecha, un alto grado de impunidad. Desde luego que todo esto tiene que ver con la política, la situación del país es finalmente, consecuencia de las políticas públicas vigentes.

No es una sorpresa que datos como estos se visibilicen con mayor intensidad en un año electoral. 2018 es para este país latinoamericano un año de precampañas y campañas en que se decide quien encabezará el ejecutivo por los próximos seis años es, desde luego, un flujo millonario abundante para los medios, la Presidencia de la República es el bocado más apetitoso de las élites de poder. Como bien apunta Mancinas-Chávez (2008), "La historia de la prensa mexicana revela que la gran mayoría de los periódicos diarios se han fundado en momentos de coyuntura política o ante la necesidad de expansión o adquisición de poder por parte de algún grupo empresarial." (p. 184).

Pero, ¿qué efecto tienen las estrategias mediáticas y propagandísticas en el ciudadano de a pie?, Harari (2016) lo entrevé y expresa elocuentemente cuando apunta que: "Cuando el ciudadano se halla detrás de la cortina de la cabina, a punto de votar, el liberalismo democrático le instruye para que consulte su conciencia y elija aquel candidato o partido que represente sus deseos más íntimos. Pero por razones difíciles de explicar, cuando está allí, tras la cortina, en verdad no recuerda todo lo que ha sentido y pensado en los años transcurridos desde las últimas elecciones. En buena medida porque le ha bombardeado un aluvión de propaganda que bien podría estar distorsionando su decisión”. 
Por espacio de seis largos años pudo haber estado quejándose constantemente de la política del régimen, del partido y del presidente en funciones, ejerciendo su derecho de libre expresión, con las precauciones debidas, diciendo a quien quisiera escucharle que será la debacle si en las próximas elecciones de nuevo se le concede el triunfo al candidato oficial. Sin embargo, pocos meses antes de las elecciones, el gobierno eleva minúsculamente el salario, pero lo pregona hasta el cansancio y gasta generosamente el dinero en despensas y placebos a la población.

"El partido gobernante -continúa Harari-, contrata a los mejores creativos de los medios para que conduzcan una campaña brillante, con una mezcla bien equilibrada de amenazas y promesas que van dirigidas directamente al centro del miedo de su cerebro. La mañana de la elección, se levanta pensando en aquello que le dé mayor seguridad y estabilidad por encima de todas las demás consideraciones y voilá, vota por el hombre que será la 'ruina del país' durante los próximos 6 años"(Pp.257). Aunque no constituye una norma infalible, ha venido ocurriendo con regularidad.

La agenda internacional reúne también múltiples elementos en cartera, como la crisis de Venezuela, la guerra de Siria y el E.I., los innumerables casos de corrupción de gobernadores, presidentes y expresidentes y, de manera relevante, las políticas proteccionistas, discriminatorias y beligerantes de Donald Trump, quien la ha emprendido también contra la prensa, como parte de su estrategia mediática, dirán algunos analistas, quienes consideran que este singular personaje ha llegado a la Casa Blanca promovido por las grandes cadenas televisivas norteamericanas, porque aunque puede ser un peligro para el mundo, "es muy buen negocio para las empresas del sector". (Regeneración $17 / 08 / 16)$

Dicho manejo informativo, reclama con urgencia buscar maneras para contribuir a la consecución del objetivo 16 para el desarrollo sostenible mundial del horizonte 2030, planteados en la asamblea de la ONU en Nueva York en el 2015, para promover sociedades pacíficas e inclusivas, garantizar el acceso del público a la información y defender las libertades fundamentales.

La UNESCO, a través del Subdirector General de Comunicación e Información Frank La Rue, propuso el pasado agosto del 2016, en Bogotá, Colombia "La construcción de un entorno propicio para el desarrollo de medios de comunicación pluralistas e independientes en América Latina". Con la participación de parlamentarios de toda Latinoamérica, se discutieron los principales desafíos para proteger y promover la libertad de expresión en la región desde una perspectiva regulatoria y legislativa. Dicho organismo internacional considera, no sin fundamento, que hacer hincapié en la importancia de la libertad de expresión es indispensable para edificar democracias prósperas y fomentar la participación de los ciudadanos. La libertad de expresión y la seguridad de los periodistas son dos pilares importantes del Estado de derecho que, a su vez, es una condición indispensable y un resultado del buen gobierno y de un programa de desarrollo centrado en los derechos humanos (UNESCO 2016).

\section{E-MEDIOS. La mediamorfosis digital:}


El ecosistema comunicativo actual, se caracteriza por la creciente masificación del uso de Internet y sus plataformas y aplicaciones. La disminución de costos, la alta disponibilidad de los dispositivos móviles y las conexiones a la Red, han contribuido a que gradualmente se vaya cerrando la denominada brecha digital y han sido factores determinantes para la modificación de hábitos de consumo de medios; la hiperconexión y la sobresaturación informativa, hay que reconocerlo, ha generado también una tendencia a la infoxicación o infobesidad. Vivimos en un entorno digital en el que los canales de información convencionales (prensa, radio, televisión) atraviesan una dinámica de "mediamorfosis en la que buscan su supervivencia compitiendo con las interfaces digitales caracterizadas éstas últimas por el imperio del entretenimiento, la velocidad del ciclo informativo, la inmediatez y superficialidad del tratamiento de la información y la viralidad". (CortésMontalvo, Bacher y Romero-Rodríguez, 2016 p.97)

La virtualidad -señala Díaz Bernal- "es una mutación de identidad que no debe considerarse como imaginaria en tanto que es otra "realidad", con unos efectos determinados. La virtualización del mundo nos sitúa en otro nivel ontológico donde los marcos de referencia cambian según las necesidades”. (Díaz Bernal 2012, p. 180.)

La mayoría de los periódicos que tradicionalmente se distribuyen en papel han abierto sus portales en internet, continuamente surgen periódicos digitales con otras reglas que les permiten ser más críticos y directos. Como ha señalado Baudrillard, "Se producen de esta manera cambios en las relaciones de experiencia y en el modo como las personas interpretan la realidad. Ya no hay una sola realidad sino diferentes perspectivas. Esta experiencia viene condicionada por lugares, individuos, que son ajenos a la persona que tiene esta experiencia. Se puede decir que lo que domina en la vida cotidiana es la virtualidad, el espectáculo, la apariencia, el simulacro". (Baudrillard, 2005, p. 13)

Una característica fundamental y distintiva de los recursos digitales, es su capacidad interactiva, la posibilidad de los usuarios de reelaborar informaciones, comentarlas, dotarlas de relevancia y difundirlas masivamente a través de las redes sociales. A principios de siglo, los investigadores tenían claro que "los informativos estaban al servicio de la ideología dominante, de forma similar a otros programas. Las informaciones de los medios de comunicación en general, pasaban por varios filtros hasta llegar al receptor: grandes agencias de información de prensa y audiovisuales, línea editorial del propio medio, derivada a su vez de intereses mercantiles y sociopolíticos" (Reig, 2001, p. 182). Casi dos décadas después las cosas han cambiado, así, una nota no cobra actualidad tanto por el mimetismo de los medios, como ocurría en el pasado, como por la viralidad que adquiere en su difusión, que suele ser inmediata, de duración relativamente corta, pero que se expande en oleadas que tienen por lo regular impacto y repercusiones casi simultáneas.

Tomamos de nuevo como referencia a la UNESCO porque es un organismo internacional cuya labor se encamina, declaradamente, a promover el acceso universal a la información,como parte del logro de los objetivos para el desarrollo sostenible del horizonte 2030, que ya se ha mencionado renglones atrás, dicha labor impulsa, a nivel mundial, el desarrollo de infraestructuras resilientes y el fomento de la innovación, especialmente mediante la ampliación del acceso a las tecnologías de la información y la comunicación (TIC). Por citar un ejemplo, la iniciativa "YouthMobile, (YoMo), tiene por objeto enseñar a 
los jóvenes a atenuar los problemas en materia de desarrollo sostenible planteados en su contexto geográfico inmediato mediante la búsqueda de soluciones pertinentes de aplicaciones móviles en lenguas vernáculas. Esta iniciativa trata de sacar partido del enorme incremento del número, el alcance y la asequibilidad de los teléfonos móviles inteligentes en todo el mundo, y también intenta aprovechar la energía y la capacidad intuitiva de los jóvenes nacidos en la era digital" (UNESCO 2016). Este ejemplo nos enlaza directamente al tercer punto, a una importante acción remedial que tiene que ver con la educación en medios.

\section{REMEDIOS: dar voz a los sin voz.}

El flujo continuo de datos que no acaban de escurrirse en vertientes, vericuetos y derivaciones noticiosas cuando ya se tiene un nuevo asunto en la agenda, permite constatar qué si bien vivimos en un mundo de abundante información, no por ello estamos mejor informados. Un torrente de información nos satura cotidianamente, es un hecho evidente y nadie lo pone en duda. Los medios de comunicación convencionales y la red de Internet proporcionan a diario una enorme cantidad de datos que por lo regular somos incapaces de asimilar por completo. El volumen de información supera, en la mayoría de casos, nuestra capacidad intelectual de recepción y procesamiento, este hecho no implica, tampoco, que la información que nos envuelve proporcione automáticamente más conocimiento, más saber. "Existe una reiterada convicción de que la información transmitida por los medios no favorece el pensamiento, muy a menudo el resultado es todo lo contrario, lo que obtenemos es desinformación, superficialidad y manipulación." (Díaz Bernal 2012, p. 182)

Somos de la opinión de que la formación de ciudadanía con acento humanístico es el primer camino que los medios deben recorrer. El problema que más indigna a la sociedad de hoy es la falta de calidad humana en lo que los medios difunden, que nos espetan a diario la violación de los derechos humanos, el desprecio a la vida, la violencia, el secuestro, el terrorismo, las guerras, la exclusión, la falta de calidad educativa, la alienación consumista, la corrupción política y el sinsentido. La vida cotidiana sufre un desgaste lento de indignación impotente.

Falta una clara alternativa de fraternidad, de consciencia acerca de que los medios no solamente son para informar y entretener, sino que son instancias educativas poderosas y también mecanismo inexplotado para dar voz a quienes no tienen manera de hacerse oír.

La educación contemporánea fomenta el aprendizaje del lenguaje multimedia para adquirir la competencia comunicativa en sus ámbitos y dimensiones tecnológicas y digitales, de este modo, en todas las etapas del currículo académico, desde la educación infantil hasta los estudios universitarios, está presente la noción de la comunicación como habilidad individual, grupal y también social. No obstante, en contados programas educativos se incide directamente en su dimensión mediática y audiovisual, como una clave expresiva sustancial del mundo que habitamos, independientemente del soporte o tecnología en el que esté representado. 
Un enorme desafío de las democracias latinoamericanas contemporáneas es que los comunicadores comprendan y asuman su responsabilidad de abogar por los derechos comunicacionales de múltiples colectivos, en sociedades controladas fundamentalmente por intereses y perspectivas político-económicas, donde el bienestar social es considerado bien condición menor, o bien consecuencia casual y meritoria, no sorprende que la comunicación periodística tienda a reproducir y amplificar la discriminación que sufren a diario niñas y niños, adolescentes, mujeres, grupos indígenas, discapacitados y los sectores más depauperados de la sociedad.

En los medios de información masiva difícilmente sus voces y sus opiniones encuentran espacio. Por ello resulta impostergable que los comunicadores y las audiencias se capaciten, conozcan los derechos que corresponden a los más jóvenes y a la diversidad de grupos que conforman el tejido social. La formación debe incluir la urgencia de consultar voces diversas, esto es indispensable para ampliar la aportación de los medios en la construcción de democracias en las que haya espacio para todos los ciudadanos. Por esa razón es importante promover la educación mediática como estrategia tanto para el análisis crítico de la información como para la posibilidad de generar y colocar mensaje, favorecer una sociedad inclusiva del conocimiento: dar voz a los sin voz, los 'sin voz' porque no tienen modo de expresar sus propios puntos de vista ya que carecen de los recursos mediáticos ubicuos para generar y difundir mensaje propio, como es el caso de los grupos indígenas, los habitantes de muchas zonas rurales, los jóvenes desempleados, la comunidad lésbico-gay y hasta las víctimas enganchadas en el tenebroso mundo de la trata y explotación sexual, los sicarios y el narcotráfico, guardando, desde luego las debidas proporciones.

Recuperamos aquí de nuevo y para terminar, el enfoque de la UNESCO con respecto al desarrollo de los medios de comunicación e información, creemos que no deja de ser un referente útil ya que se centra en el conocimiento y tiene en cuenta el contexto, tomando en consideración los problemas y oportunidades que crea la rápida evolución del entorno tecnológico digital. La iniciativa del multicitado organismo no sólo pone de relieve la importancia que tiene la generación y el aprovechamiento compartido del conocimiento para impulsar el desarrollo de los medios de comunicación e información, sino que además es especialmente pertinente para un enfoque inclusivo destinado a reforzar la educación para la comunicación y para los medios en todos los niveles educativos, no solo en las disciplinas afines a los periodistas y comunicadores, sino en todas. Educar en comunicación no significa querer hacer a todos periodistas, de la misma manera que educar en salud no pretende convertir a toda la gente en médicos. La educación preventiva para los medios y la comunicación, contribuye también al logro de los objetivos en el horizonte de las naciones para el año 2030.

Según la UNESCO (AMI, 2011), la educación en medios debe favorecer la creación de una conciencia crítica de los usuarios. Para ello, se propugna que los programas educativos abarquen desde el análisis de contenido de los mensajes mediáticos hasta la utilización de los instrumentos de expresión creadora, sin dejar de lado la utilización de los canales de participación activa. El acceso a todo tipo de mensajes sin barreras espacio-temporales es 
un hecho, pero hay que potenciar el análisis y la reflexión como mecanismos de filtro y defensa crítica ante la sobresaturación informativa, lo que Desantes (2004) denomina la "infopolución".

Los medios de comunicación se encuentran actualmente atravesando una etapa de adaptación severa que no solamente significa un cambio de plataformas hacia las pantallas y dispositivos digitales, sino un cambio $\square$ de paradigma en el ecosistema comunicativo, modificando los modelos tanto en cuanto al acceso público a la información, como del ejercicio del periodismo. La educación en medios es una de las claves para que las nuevas generaciones tengan acceso a una ciudadanía plena. Sin embargo, a pesar de que la conectividad interactiva se ha saturado de pantallas, las políticas de formación de docentes y de comunicadores enfrentan aún muchos rezagos.

\section{REFERENCIAS}

Baudrillard, J. (2005). Cultura y Simulacro. Barcelona: Kairós.

Cortés-Montalvo, J.A., Bacher, S., Romero-Rodríguez, L. (2016). Alfabetización mediática en la formación del profesorado y comunicadores. Journal of Media Literacy, Vol. $62 \mathrm{~N}^{\circ} 1$ $\& 2$.

Desantes-Guanter, J. M. (2004) Derecho a la información Materiales para un sistema de la comunicación. Valencia: Fundación COSO.

Díaz Bernal, J.G. (2012). Análisis histórico sobre la sociedad de la información y el conocimiento. Praxis del Saber. Vol. 3, N 5, pp. 167-186, Bogotá.

Gabelas-Barroso, J. A.; Marta-Lazo, C., y Hergueta-Covacho, E. (2013). El Factor Relacional como epicentro de las prácticas culturales digitales. En Aranda, D., Creus; A. y Sánchez Navarro, J. (Ed.), Educación, Medios y Cultura de la Participación(351-374). Barcelona: Editorial UOC.

Gunviolence Archives. (2017) http://www.gunviolencearchive.org.

Harari, Y. N. (2016), Homo Deus. Colección DEBATE, Penguin Random House.

Mancinas-Chávez, R. (2008), El poder mediático en México. Relaciones entre economía, política y medios de comunicación. Colección ámbitos para la comunicación N9, Sevilla.

Periódico Regeneración. (02/08/2016) "Estos son los periodistas asesinados en Veracruz con Duarte" http://regeneracion.mx.

Periódico Regeneración (17/08/2016) “Lo que los medios de información no dicen sobre las elecciones en E.U. http://regeneracion.mx/lo-que-los-medios-de-informacion-no-dicensobre-las-elecciones-en-eu/.

Reig, R. (2001). El éxtasis cibernético, Comunicación, democracia y neototalitarismo a principios del siglo XXI. Ediciones libertarias, Madrid. 
Secretaría de Gobernación, México (2018), Secretariado del Sistema Nacional de Seguridad Pública, (Consultado el 02.02.2017) http://secretariadoejecutivo.gob.mx/docs/pdfs/victimas/Victimas2016_062016.pdf.

Torres, J.M. (2016). El pulso de la república. https://www.elpulsodelarepublica.com UNESCO, (2011): Alfabetización Mediática e Informacional, Currículum para Profesores. Disponible en: http://unesdoc.unesco.org/images/0021/002160/216099s.pdf.

UNESCO(2016). UNESCO apoya el desarrollo de medios de comunicación plurales e independientes en América Latina09.08.2016 - Comunicación e Información. http://www.unesco.org/new/es/communication-and-information/resources/news-and-infocus-articles/in-focus-articles/2016/pluralistic-and-independent-media-in-latin-america/

\section{BREVE SEMBLANZA DEL AUTORE:}

Jorge Abelardo Cortés Montalvo es catedrático titular en la Maestría en Innovación educativa y en el programa de doctorado en Educación, Artes y Humanidades de la Facultad de Filosofía y Letras de la Universidad Autónoma de Chihuahua (México). Doctor en en Ciencias de la Información, Comunicación y Periodismo por la Universidad de Sevilla, es miembro del Sistema Nacional de Investigadores (SNI, Nivel I, Reg. 22024) y del Cuerpo Académico Consolidado de Educación y Comunicación. Coordinador del capítulo México de la Red Internacional de Alfabetización Mediática (ALFAMED), miembro fundador de la Red Académica Iberoamericana de Comunicación (RAIC) y de la Sociedad Latina de Comunicación Social (SLCS).

- Recibido: 23/02/2018

- Aceptado: 01/03/2018

Ámbitos. Revista Internacional de Comunicación, n.40, edición de primavera, 2018. 